DOI: 10.12731/2070-7568-2021-10-1-23-37

УДК 330.43:338

\title{
АНАЛИЗ КЛАСТЕРИЗАЦИИ \\ СОЦИАЛЬНО-ЭКОНОМИЧЕСКОГО РАЗВИТИЯ РЕГИОНОВ ЮГА РОССИИ ДО И ПОСЛЕ ВВЕДЕНИЯ МЕЖДУНАРОДНЫХ САНКЦИЙ
}

\section{Гичиев Н.С.}

Усиление региональной дифференциащии создает проблемы для проведения эффективной государственной политики, связанной с выравниванием социально-экономического развития регионов страны и приближением их характеристик к уровням более развитых стран. В результате перетока капитала и трудоспособного населения из бедных регионов в богатые повышается риск региональных кризисов и межрегиональных конфликтов, поэтому дифференциация в этом случае дестимулирует развитие и ее приходится снижать. Для решения отмеченной проблемы необходимо на основе кластерного анализа оченить уровень дифференицации социально-экономического развития проблемных регионов Юга России.

Цель исследования: на основе кластерного анализа определить уровень диф-ференцииачи социально-экономического развития регионов Юга России до и после введения антироссийских санкиий.

Метод или методология проведения работы: в статье использовались экономико-статистические методы анализа

Результаты: в статье представлены результаты кластерного анализа регионов Южного и Северо-Кавказского федеральных округов по уровню показателей их сочииально-экономического развития и демографического положения до и после введения антироссийских санкций.

Область применения результатов: полученные результаты исследования могут применяться при разработке Стратегии со- 
цุиально-экономического развития Северо-Кавказского федерального округа на период до 2035 года.

Ключевые слова: кластерный анализ; округ; регион; соичильноэкономические показатели; демографические показатели; территориальные кластеры.

\section{ANALYSIS OF THE CLUSTERIZATION OF THE SOCIO-ECONOMIC DEVELOPMENT OF REGIONS OF SOUTH RUSSIA BEFORE AND AFTER INTRODUCTION INTERNATIONAL SANCTIONS}

\section{Gichiev N.S.}

Strengthening regional differentiation creates problems for the implementation of an effective state policy associated with the equalization of the socio-economic development of the regions of the country and the approach of their characteristics to the levels of more developed countries. As a result of the flow of capital and the working-age population from poor regions to rich regions, the risk of regional crises and interregional conflicts increases, so differentiation in this case discourages development and has to be reduced. To solve the noted problem, it is necessary, on the basis of cluster analysis, to assess the level of differentiation of the socio-economic development of the problem regions of the South of Russia.

Purpose of the study: on the basis of cluster analysis, to determine the level of differentiation of the socio-economic development of the regions of the South of Russia before and after the introduction of anti-Russian sanctions.

Method or methodology of the work: the article used economic and statistical methods of analysis.

Results: the article presents the results of a cluster analysis of the regions of the Southern and North Caucasian Federal Districts in terms of the level of indicators of their socio-economic development and demographic situation before and after the introduction of anti-Russian sanctions. 
Field of application of the results: the obtained results of the study can be used in the development of the Strategy of socio-economic development of the North Caucasus Federal District for the period up to 2035.

Keywords: cluster analysis; district; region; socio-economic indicators; demographic indicators; territorial clusters.

\section{Введение}

В современных исследованиях вопросы пространственного развития территорий раскрываются с разных теоретико-методологических и научно-практических позиций [1, с. 111-115].

Кластерный анализ - это метод классификационного анализа; его основное назначение - разбиение множества исследуемых объектов и признаков на однородные в некотором смысле группы, или кластеры. Это многомерный статистический метод, поэтому предполагается, что исходные данные могут быть значительного объема, т.е. существенно большим может быть, как количество объектов исследования (наблюдений), так и признаков, характеризующих эти объекты.

В рамках реализации поставленной цели основными задачами кластерного анализа являются: разбиение регионов Юга России на однородные группы по нескольким группировочным признакам одновременно, оценка изменений внутрикластерной группировки южных российских регионов (СКФО+ЮФО) до и после введения международных санкций, пространственно-экономическая характеристика основных кластеров.

В качестве главного инструмента анализа использовался один из методов многомерной статистики - кластерный анализ. Средствами проведенного анализа являлись табличный процессор Excel и программный комплекс Statistica.

\section{Материалы и методы}

Мировой экономический ландшафт показывает кластерную перспективу [19, pp. 215-232; 21], которая имеет тенденцию распространяться на весь экономический спектр. Например, Силиконовая долина в Калифорнии вызвала интерес к созданию кластеров ин- 
формационно-коммуникационных технологий [ИКТ] по всему миру. Аналогичные кластеры ИКТ были внедрены в Европе [7, pp. 452457] и развивающихся странах, включая Индию [14, pp. 664-685] и Китай [20, pp. 827-850; 22, pp. 1113-1134]. Кроме того, тенденция развития кластеров является свидетелем в большом разнообразии отраслей промышленности, включая финансы и производителем услуг [9, рр. 67-90; 17, р. 3], рекреация, культура и средства массовой информации [8, pp. 1819-1841; 13 рр. 507-532; 18, pp. 479501] и электронного бизнеса [5, pp. 1431-1444], а также традиционных отраслей, например, текстильной, кожевенной, керамической и мебельной.

Финансовые кластеры городских агломераций в основном формируются в центральной части города не только из-за его доступного расположения, но также из-за его близости к клиентам, информации и удобства личного контакта в предпринимательской деятельности [11, pp. 563-577; 18, pp. 971-989]. Пространственно-экономическая характеристика основных кластеров представлена в таблице 1.

Таблица 1.

\section{Пространственно-экономическая характеристика основных кластеров}

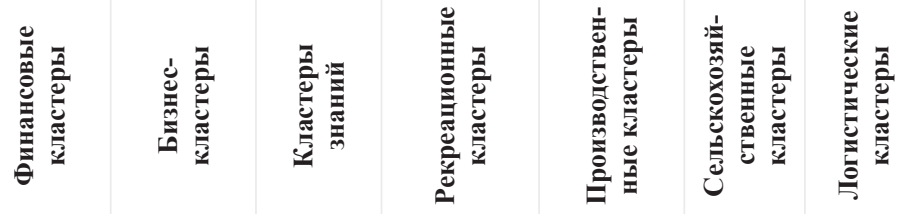

\begin{tabular}{|c|c|c|c|c|c|c|c|}
\hline $\begin{array}{l}\text { Основные } \\
\text { факторы } \\
\text { агломера- } \\
\text { ции }\end{array}$ & $\begin{array}{l}\text { Зависимость } \\
\text { от маршру- } \\
\text { та, личные } \\
\text { контакты, } \\
\text { выгодное } \\
\text { расположе- } \\
\text { ние и гео- } \\
\text { графическая } \\
\text { близость }\end{array}$ & $\begin{array}{l}\text { Деловая } \\
\text { конкурен- } \\
\text { ция, личные } \\
\text { контакты, } \\
\text { динамичная } \\
\text { Деловая сре- } \\
\text { да, выгодное } \\
\text { расположе- } \\
\text { ние }\end{array}$ & $\begin{array}{l}\text { Побочные } \\
\text { эффекты } \\
\text { знаний, } \\
\text { личные } \\
\text { контакты }\end{array}$ & $\begin{array}{l}\text { Социальный } \\
\text { фактор, } \\
\text { ВКЛ. стиль } \\
\text { жизни и } \\
\text { культура, } \\
\text { приятная / } \\
\text { уникальная } \\
\text { окружающая } \\
\text { среда }\end{array}$ & $\begin{array}{l}\text { Промыш- } \\
\text { ленные } \\
\text { традиции } \\
\text { и ресурс- } \\
\text { ные пре- } \\
\text { имущества, } \\
\text { глобальная } \\
\text { торговля и } \\
\text { разделение } \\
\text { труда, про- } \\
\text { мышленная } \\
\text { специали- } \\
\text { зация }\end{array}$ & $\begin{array}{l}\text { Эффек- } \\
\text { тивность } \\
\text { сельско- } \\
\text { хозяй- } \\
\text { ственного } \\
\text { произ- } \\
\text { водства, } \\
\text { дефицит } \\
\text { земли }\end{array}$ & $\begin{array}{l}\text { Доступ- } \\
\text { ность и } \\
\text { качество } \\
\text { инфра- } \\
\text { структу- } \\
\text { ры }\end{array}$ \\
\hline
\end{tabular}




\begin{tabular}{|c|c|c|c|c|c|c|c|}
\hline & 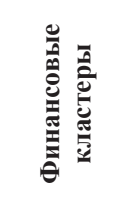 & 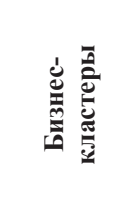 & 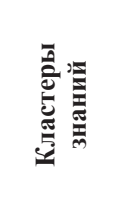 & 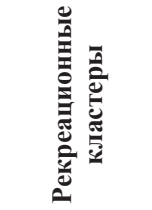 & 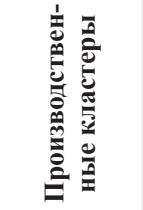 & 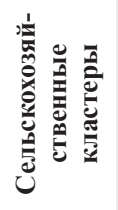 & 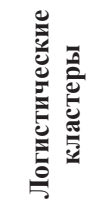 \\
\hline $\begin{array}{l}\text { Основные } \\
\text { виды } \\
\text { экономи- } \\
\text { ческой } \\
\text { деятель- } \\
\text { ности }\end{array}$ & $\begin{array}{l}\text { Банки, } \\
\text { страховые } \\
\text { компании, } \\
\text { Финансовые } \\
\text { рынки, бух- } \\
\text { галтерские } \\
\text { услуги }\end{array}$ & $\begin{array}{l}\text { Менед- } \\
\text { жмент, } \\
\text { профессио- } \\
\text { нальные, в } \\
\text { частности } \\
\text { ИТ-услуги, } \\
\text { Консалтинг, } \\
\text { реклама и } \\
\text { медиа-инду- } \\
\text { стрии }\end{array}$ & $\begin{array}{l}\text { Синергия } \\
\text { универ- } \\
\text { ситетов и } \\
\text { отраслей } \\
\text { промыш- } \\
\text { ленности, } \\
\text { или твор- } \\
\text { ческие } \\
\text { услуги, } \\
\text { связанные } \\
\text { с куль- } \\
\text { турой и } \\
\text { знаниями }\end{array}$ & $\begin{array}{l}\text { Отели, } \\
\text { рестораны, } \\
\text { кафе, уличная } \\
\text { жизнь, ночная } \\
\text { жизнь и ре- } \\
\text { креационные } \\
\text { магазины }\end{array}$ & $\begin{array}{l}\text { Крупносе- } \\
\text { рийное про- } \\
\text { изводство с } \\
\text { проситель- } \\
\text { ной сетью } \\
\text { поставщиков } \\
\text { и вспомо- } \\
\text { гательных } \\
\text { агентств }\end{array}$ & $\begin{array}{l}\text { Агро- } \\
\text { комплекс } \\
\text { с фермер- } \\
\text { ством, } \\
\text { произ- } \\
\text { водством } \\
\text { продуктов } \\
\text { питания и } \\
\text { туризмом }\end{array}$ & $\begin{array}{l}\text { Муль- } \\
\text { тимо- } \\
\text { дальные } \\
\text { транс- } \\
\text { портные } \\
\text { и рас- } \\
\text { предели- } \\
\text { тельные } \\
\text { центры } \\
\text { регио- } \\
\text { нального } \\
\text { или } \\
\text { нацио- } \\
\text { нального } \\
\text { значения }\end{array}$ \\
\hline $\begin{array}{l}\text { Располо- } \\
\text { жение }\end{array}$ & $\begin{array}{l}\text { Центр го- } \\
\text { рода }\end{array}$ & $\begin{array}{l}\text { Центр горо- } \\
\text { да или под- } \\
\text { центры }\end{array}$ & $\begin{array}{l}\text { Внутрен- } \\
\text { ний город, } \\
\text { окраин- } \\
\text { ный город } \\
\text { или При- } \\
\text { городный } \\
\text { район }\end{array}$ & $\begin{array}{l}\text { Внутрен- } \\
\text { ний город, } \\
\text { окраинный } \\
\text { город или } \\
\text { Пригородный } \\
\text { район }\end{array}$ & $\begin{array}{l}\text { Городская } \\
\text { окраина, } \\
\text { транспорт- } \\
\text { ный коридор }\end{array}$ & $\begin{array}{l}\text { При- } \\
\text { городные } \\
\text { или при- } \\
\text { городные } \\
\text { города }\end{array}$ & $\begin{array}{l}\text { Транс- } \\
\text { портные } \\
\text { Примеча- } \\
\text { ния [воз- } \\
\text { душные, } \\
\text { морские, } \\
\text { автомо- } \\
\text { бильные, } \\
\text { железно- } \\
\text { дорож- } \\
\text { ные] }\end{array}$ \\
\hline $\begin{array}{l}\text { Встроен- } \\
\text { ные связи } \\
\text { с городами }\end{array}$ & $\begin{array}{l}\text { Финансовая } \\
\text { система }\end{array}$ & $\begin{array}{l}\text { Деловая } \\
\text { среда, со- } \\
\text { трудниче- } \\
\text { ство фирм }\end{array}$ & $\begin{array}{l}\text { Институты } \\
\text { поддержки } \\
\text { и таланты }\end{array}$ & $\begin{array}{l}\text { Конвергенция } \\
\text { культуры и } \\
\text { [восходящего] } \\
\text { среднего } \\
\text { класса }\end{array}$ & $\begin{array}{l}\text { Сильно } \\
\text { зависит } \\
\text { от других } \\
\text { кластеров }\end{array}$ & $\begin{array}{l}\text { Сильно } \\
\text { зависит } \\
\text { от других } \\
\text { кластеров }\end{array}$ & $\begin{array}{l}\text { Логисти- } \\
\text { ческая } \\
\text { система }\end{array}$ \\
\hline $\begin{array}{l}\text { Простран- } \\
\text { ственные } \\
\text { сигнатуры }\end{array}$ & $\begin{array}{l}\text { Достопри- } \\
\text { мечательно- } \\
\text { сти города }\end{array}$ & $\begin{array}{l}\text { Огромный } \\
\text { объем дело- } \\
\text { вых и торго- } \\
\text { вых зданий }\end{array}$ & $\begin{array}{l}\text { Расчесы- } \\
\text { вание с } \\
\text { универ- } \\
\text { ситетами } \\
\text { или инсти- } \\
\text { тутами, с } \\
\text { высоко- } \\
\text { качествен- } \\
\text { ной атмос- } \\
\text { ферой }\end{array}$ & $\begin{array}{l}\text { Стильная, } \\
\text { модная или } \\
\text { живописная } \\
\text { обстановка }\end{array}$ & $\begin{array}{l}\text { Индустри- } \\
\text { альный парк }\end{array}$ & $\begin{array}{l}\text { Вероятно, } \\
\text { слабо } \\
\text { распреде- } \\
\text { лены }\end{array}$ & $\begin{array}{l}\text { Огромная } \\
\text { транс- } \\
\text { портная } \\
\text { инфра- } \\
\text { структура }\end{array}$ \\
\hline $\begin{array}{l}\text { Типичный } \\
\text { пример }\end{array}$ & $\begin{array}{l}\text { Лондон- } \\
\text { ский Сити, } \\
\text { Нижний и } \\
\text { Средний } \\
\text { Манхэттен }\end{array}$ & Манхеттен & $\begin{array}{l}\text { Сили- } \\
\text { коновая } \\
\text { долина, } \\
\text { маршрут } \\
128, \text { IT- } \\
\text { кластеры в } \\
\text { Бангалоре } \\
\text { и Пекине }\end{array}$ & $\begin{array}{l}\text { Орландо в } \\
\text { США и улица } \\
\text { Ла Рамбла в } \\
\text { Барселоне }\end{array}$ & $\begin{array}{l}\text { Нефть в } \\
\text { Техасе, про- } \\
\text { изводство } \\
\text { автомобилей } \\
\text { в Детройте }\end{array}$ & $\begin{array}{l}\text { Садо- } \\
\text { водство } \\
\text { в Нидер- } \\
\text { ландах }\end{array}$ & $\begin{array}{l}\text { Схипхол } \\
\text { и Роттер- } \\
\text { дам }\end{array}$ \\
\hline
\end{tabular}


В этой связи необходимо отметить, что экономические детерминанты стратегии кластеризации ориентированы на эффекты агломерации и, связанных с ними цепочек поставок [12, рр. 39-49], инновационных систем [2, pp. 299-330], переток знаний [3, pp. 31-56], и взаимодействие между предприятиями и/или учреждениями [10, pp. 483-499, 19]. Если кластер преуспевает в одном или нескольких аспектах, упомянутых выше, то фирмы данного кластера могут извлечь выгоду из повышения производительности, снижения затрат и улучшения качества продукции [4, pp. 335-355].

В целом развитие кластеров стимулирует развитие весьма специфического территориального процесса, выступающего в качестве промежуточной системы между микроэкономикой и структурой современной экономики [18, pp. 479-501]. Процесс развития кластеризации связан с формированием центра кластера [ядра кластера] из-за его выгодной пространственной доступности [18, pp. 479-501], что формирует ландшафт интенсивной концентрации экономической деятельности в виде функционально специализированных районов [18, pp. 479-501].

Учитывая важность выявления и оценки динамики процессов кластеризации российских регионов в составе Северо-Кавказского и Южного (ЮФО) федеральных округов, в нашем исследовании представлен их кластерный анализ на основе статистических факторов, наиболее информативно характеризующих условия развития данных регионов.

В целом решение задач кластерного анализа должно удовлетворять требованиям критерия оптимальности (формула 1).

$$
W=\sigma_{n}=\sum_{j=1}^{n}\left(x_{j}-\bar{x}\right)^{2}=\sum_{j=1}^{n} x_{j}^{2}-\frac{1}{n}\left[\sum_{j=1}^{n} x_{j}\right]^{2}
$$

где $x^{j}-$ представляет собой измерения $j$-го объекта.

В кластерном анализе для количественной оценки сходства вводится понятие метрики. Сходство или различие между классифицируемыми объектами устанавливается в зависимости от метрического расстояния между ними. Если каждый объект описывается 
k признаками, то он может быть представлен как точка в k-мерном пространстве, и сходство с другими объектами будет определяться как соответствующее расстояние.

Объединение или метод древовидной кластеризации используется при формировании кластеров несходства или расстояния между объектами. Эти расстояния могут определяться в одномерном или многомерном пространстве.

Результаты кластерного анализа и группировки регионов представлены для 2014 г. (до введения антироссийских санкций) и 2017 г. (после введения антироссийских санкций).

Статистическое моделирование проводилось в программном комплексе STATISTICA. Дендрограмма кластеров по 15 исследуемым регионам Северо-Кавказского и Южного федеральных округов представлена на рисунках 1-2, где на оси абсцисс отложено расстояние между парами объектов или кластеров в процентах от максимально возможного расстояния в группе наблюдений, а по оси ординат показаны номера регионов в соответствии с таблицей. Анализ позволил выявить несколько групп кластеров.

\section{Результаты и обсуждение}

В качестве показателей социально-экономического развития (СЭР) выбраны восемь показателей: индекс физического объема валового региональный продукт, среднедушевые денежные доходы населения (по средневзвешенному курсу \$ месяц), инвестиции в основной капитал на душу населения (по средневзвешенному курсу \$), объем отгруженных товаров обрабатывающих производств (по средневзвешенному курсу \$), продукция сельского хозяйства (по средневзвешенному курсу \$), оборот розничного торговли (по средневзвешенному курсу \$), численность безработных.

В нашем исследовании кластерный анализ выполнен методом евклидовых расстояний, который принадлежит к группе итеративных методов эталонного типа. 


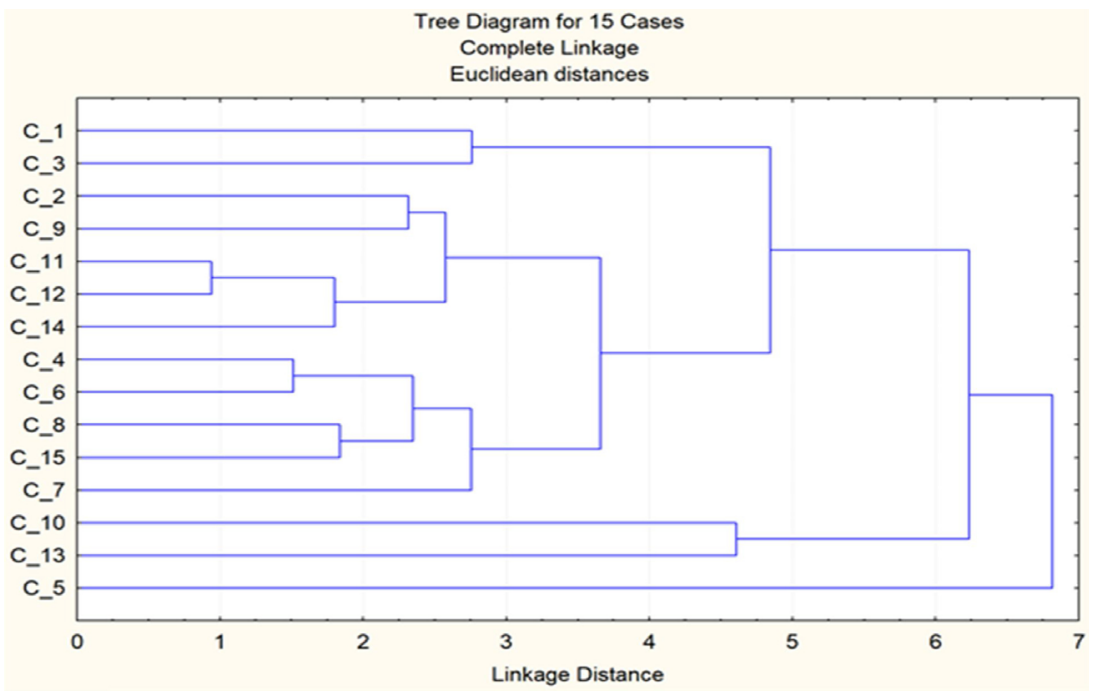

Рис. 1. Дендрограмма кластеров по уровню СЭР СКФО-ЮФО после введения международных санкций (2017 г.)

Кластерный анализ по восьми показателям СЭР на 2017 г. (после введения международных санкций), когда расстояние между кластерами не превышает одно стандартное отклонение, выявил 7 кластеров: 1 кластер: Республика Адыгея, г. Севастополь; 2 кластер: Кабардино-Балкарская Республика, Республика Северная Осетия; 3 кластер: Республика Крым, Астраханская область; 4 кластер: Республика Калмыкия, Карачаево-Черкесская Республика, Республика Ингушетия; 5 кластер: Чеченская Республика; 6 кластер: Волгоградская область, Республика Дагестан, Ставропольский край; 7 кластер: Краснодарский край. Ростовская область.

Кластерный анализ по восьми показателям СЭР на 2017 г. (после введения международных санкций), когда расстояние между кластерами не превышает одно стандартное отклонение, также выявил 7 кластеров: 1 кластер: Краснодарский край; 2 кластер: Республика Дагестан, Ставропольский край; 3 кластер: Волгоградская область, Ростовская область; 4 кластер: Чеченская Республика; 5 кластер: Республика Крым, г. Севастополь, Кабардино-Балкарская Респу- 
блика, Карачаево-Черкесская Республика; 6 кластер: Республика Калмыкия. Республика Ингушетия; 7 кластер: Республика Адыгея, Астраханская область, Республика Северная Осетия.

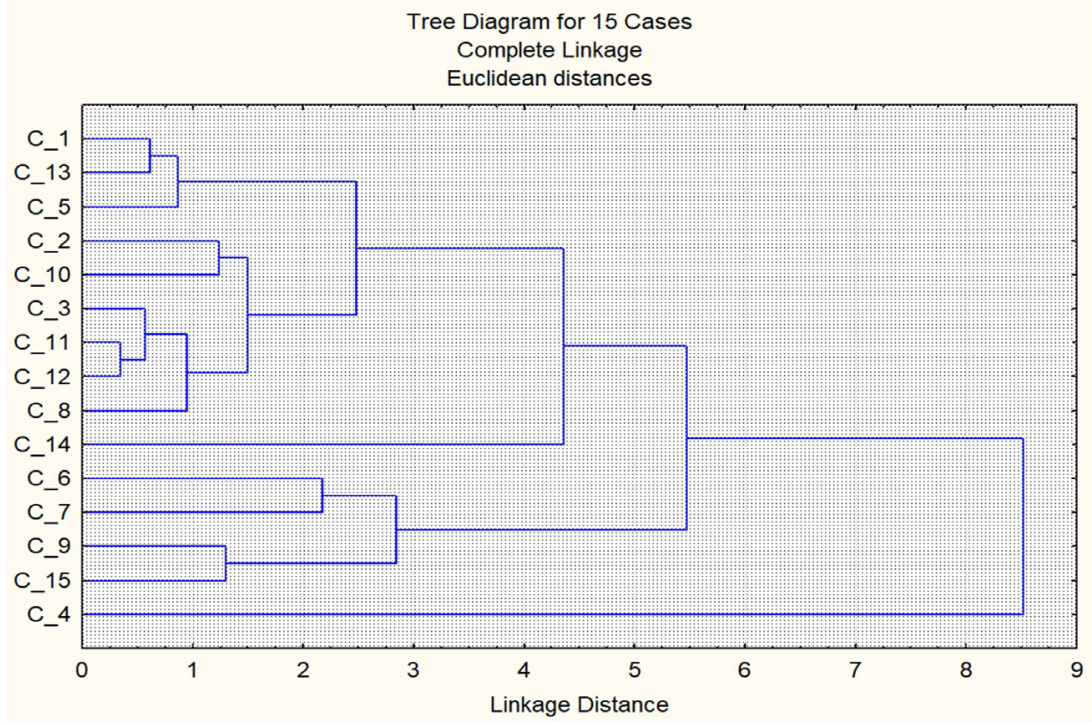

Рис. 2. Дендрограмма кластеров по уровню СЭР СКФО-ЮФО до введения международных санкций (2014 г.)

Интегральная оценка результатов кластерного анализа по восьми выбранным показателям СЭР до и после введения антироссийских санкций представлена в таблице 2 .

Таблица 2.

Принадлежность к кластерам

\begin{tabular}{|c|c|c|c|}
\hline № & $\begin{array}{c}2014 \text { г. } \\
\text { (до введения } \\
\text { международных санкций) }\end{array}$ & № & $\begin{array}{c}2017 \text { г. } \\
\text { (после введения } \\
\text { международных санкций) }\end{array}$ \\
\hline 1 & Краснодарский край & 1 & Республика Адыгея, г. Севастополь \\
\hline 2 & $\begin{array}{l}\text { Республика Дагестан, } \\
\text { Ставропольский край }\end{array}$ & 2 & $\begin{array}{l}\text { Кабардино-Балкарская Республика, } \\
\text { Республика Северная Осетия }\end{array}$ \\
\hline 3 & $\begin{array}{l}\text { Волгоградская область, } \\
\text { Ростовская область }\end{array}$ & 3 & $\begin{array}{l}\text { Республика Крым, Астраханская } \\
\text { область }\end{array}$ \\
\hline 4 & Чеченская Республика & 4 & $\begin{array}{l}\text { Республика Калмыкия, Карачаево- } \\
\text { Черкесская Республика, Республика } \\
\text { Ингушетия }\end{array}$ \\
\hline
\end{tabular}


Окончание табл. 2.

\begin{tabular}{|c|l|c|l|}
\hline 5 & $\begin{array}{l}\text { Республика Крым, г. Севастополь, } \\
\text { Кабардино-Балкарская Республика, } \\
\text { Карачаево-Черкесская Республика }\end{array}$ & 5 & Чеченская Республика \\
\hline 6 & $\begin{array}{l}\text { Республика Калмыкия. Республика } \\
\text { Ингушетия }\end{array}$ & 6 & $\begin{array}{l}\text { Волгоградская область, Республика } \\
\text { Дагестан, Ставропольский край }\end{array}$ \\
\hline 7 & $\begin{array}{l}\text { Республика Адыгея, Астраханская } \\
\text { область, Республика Северная Осетия }\end{array}$ & 7 & $\begin{array}{l}\text { Краснодарский край. Ростовская } \\
\text { область }\end{array}$ \\
\hline
\end{tabular}

Источник: расчеты автора по [23]

\section{Заключение}

Таким образом, кластерный анализ 15 российских регионов в составе СКФО и ЮФО по восьми показателям СЭР до (2014 г.) и после введения международных санкций (2017 г.) показал значительное изменение их внутрикластерной группировки, отражающей в большей степени влияние экзогенных факторов.

\section{Список литературы}

1. Орлова И.В., Филонова Е.С. Кластерный анализ регионов центрального федерального округа по социально-экономическим и демографическим показателям // Экономика, Статистика и Информатика. 2015. №5. C.111-115. https://statecon.rea.ru/jour/article/ view/832?locale=ru_RU

2. Asheim B., Isaksen A. Location, agglomeration and innovation: Towards regional innovation systems in Norway? // European Planning Studies, 1997, vol. 5, no. 3, pp. 299-330. https://doi. org/10.1080/09654319708720402

3. Bathelt H., Malmberg A., Maskell P. Clusters and knowledge: Local buzz, global pipelines and the process of knowledge creation // Progress in Human Geography, 2004, vol. 28, no. 1, pp. 31-56. https://doi. org/10.1191\%2F0309132504ph469oa

4. Belussi F., Caldari K. At the origin of the industrial district: Alfred Marshall and the Cambridge school // Cambridge Journal of Economics, 2009, vol. 33, no. 2, pp. 335-355. https://doi.org/10.1093/cje/ben041

5. Boasson V., MacPherson A. The role of geographic location in the financial and innovation performance of publicly traded pharmaceuti- 
cal companies: Empirical evidence from the United States // Environment and Planning A, 2001, vol. 33, no. 8, pp. 1431-1444. https://doi. org $/ 10.1068 \% 2 \mathrm{Fa} 3431$

6. Giuliano, G., Agarwal, A., \& Redfearn, C. Metropolitan spatial trends in employment and housing. In Special report 298: Driving and the built environment: The effects of compact development on motorized travel, energy use, and CO2 emissions. 2008. http://onlinepubs.trb.org/onlinepubs/sr/sr298giuliano.pdf

7. Hospers G.J. Best practices and the dilemma of regional cluster policy in Europe // Tijdschrift Voor Economische En Sociale Geografie, 2005, vol. 96, no. 54, pp. 452-457. https://doi.org/10.1111/j.14679663.2005.00476.x

8. Hutton T.A. Spatiality, built form, and creative industry development in the inner city // Environment and Planning A, 2006, vol. 38, no. 10, pp. 1819-1841. https://doi.org/10.1068\%2Fa37285

9. Keeble D., Nachum L. Why do business service firms cluster? Small consultancies, clustering and decentralization in London and southern England // Transactions of the Institute of British Geographers, 2002, vol. 27, no. 1, pp. 67-90. https://doi.org/10.1111/1475-5661.00042

10. Krugman P. Increasing returns and economic geography // Journal of Political Economy, 1991, vol. 99, no. 3, pp. 483-499. https://doi.org/10.1086/261763

11. McCann P. Rethinking the economics of location and agglomeration // Urban Studies, 1995, vol. 32, no. 2, pp. 563-577. https://www.jstor.org/ stable/43196292

12. McDonald F., Huang Q.H., Tsagdis D., Tuselmann H.J. Is there evidence to support porter-type cluster policies? // Regional Studies, 2007, vol. 41, no. 1, pp. 39-49. https://doi.org/10.1080/00343400601136284

13. Mommaas H. Cultural clusters and the post-industrial city: Towards the remapping of urban cultural policy // Urban Studies, 2004, vol. 41, no. 3, pp. 507-532. https://doi.org/10.1080/0042098042000178663

14. Parthasarathy B. India's Silicon Valley or Silicon Valley's India? Socially embedding the computer software industry in Bangalore // International Journal of Urban and Regional Research, 2004, vol. 28, no. 3, pp. 664685. https://doi.org/10.1111/j.0309-1317.2004.00542.x 
15. Phelps N.A. Clusters, dispersion and the spaces in between: For an economic geography of the banal // Urban Studies, 2004, vol. 41, no. 5-6, pp. 971-989. https://doi.org/10.1080/00420980410001675887

16. Porter M.E. The competitiveness advantage of nations. Basingstoke Macmillan, London, 1990.

17. Rosenfeld S.A. Bringing business clusters into the mainstream of economic development // European Planning Studies, 1997, vol. 5, no. 1, pp. 3-23. https://doi.org/10.1080/09654319708720381

18. Scott A.J. Location processes, urbanization, and territorial development: An exploratory essay // Environment and Planning A, 1985, vol. 17, no. 4, pp. 479-501. https://doi.org/10.1068/a170479

19. Scott A.J., Storper M. High technology industry and regional development: A theoretical critique and reconstruction // International Social Science Journal, 1987, vol. 112, pp. 215-232.

20. Tan J. Growth of industry clusters and innovation: Lessons from Beijing Zhongguancun Science Park // Journal of Business Venturing, 2006, vol. 21, no. 6, pp. 827-850. https://doi.org/10.1016/j.jbusvent.2005.06.006

21. The World Bank. World development report 2009: Reshaping economic geography. Washington DC, 2009. 383 p.

22.Zhou Y. The making of an innovative region from a centrally planned economy: Institutional evolution in Zhongguancun Science Park in Beijing // Environment and Planning A, 2005, vol. 37, vol. 6, pp. 1113-1134. https://doi.org/10.1068/a3716

23. Федеральная служба государственной статистики. https://rosstat.gov.ru/

\section{References}

1. Orlova I.V., Filonova E.S. Klasternyy analiz regionov tsentral'nogo federal'nogo okruga po sotsial'no-ekonomicheskim i demograficheskim pokazatelyam [Cluster analysis of the regions of the central federal district socio-economic and demographic indicators]. Ekonomika, Statistika i Informatika [Statistics and Economics], 2015, no. 5, pp. 111-115. https://statecon.rea.ru/jour/article/view/832?locale=ru_RU

2. Asheim B., Isaksen A. Location, agglomeration and innovation: Towards re-gional innovation systems in Norway? Europe- 
an Planning Studies, 1997, vol. 5, no. 3, pp. 299-330. https://doi. org/10.1080/09654319708720402

3. Bathelt H., Malmberg A., Maskell P. Clusters and knowledge: Local buzz, global pipelines and the process of knowledge creation. Progress in Human Geography, 2004, vol. 28, no. 1, pp. 31-56. https://doi. org/10.1191\%2F0309132504ph469oa

4. Belussi F., Caldari K. At the origin of the industrial district: Alfred Marshall and the Cambridge school. Cambridge Journal of Economics, 2009, vol. 33, no. 2, pp. 335-355. https://doi.org/10.1093/cje/ben041

5. Boasson V., MacPherson A. The role of geographic location in the financial and innovation performance of publicly traded pharmaceutical companies: Empirical evidence from the United States. Environment and Planning A, 2001, vol. 33, no. 8, pp. 1431-1444. https://doi.org/10.1068/a3431

6. Giuliano, G., Agarwal, A., \& Redfearn, C. Metropolitan spatial trends in em-ployment and housing. In Special report 298: Driving and the built environ-ment: The effects of compact development on motorized travel, energy use, and CO2 emissions. 2008. http://onlinepubs.trb.org/ onlinepubs/sr/sr298giuliano.pdf

7. Hospers G.J. Best practices and the dilemma of regional cluster policy in Europe. Tijdschrift Voor Economische En Sociale Geografie, 2005, vol. 96, no. 54, pp. 452-457. https://doi.org/10.1111/j.1467-9663.2005.00476.x

8. Hutton T.A. Spatiality, built form, and creative industry development in the inner city. Environment and Planning A, 2006, vol. 38, no. 10, pp. 1819-1841. https://doi.org/10.1068/a37285

9. Keeble D., Nachum L. Why do business service firms cluster? Small consul-tancies, clustering and decentralization in London and southern England. Transactions of the Institute of British Geographers, 2002, vol. 27, no. 1, pp. 67-90. https://doi.org/10.1111/1475-5661.00042

10. Krugman P. Increasing returns and economic geography. Journal of Political Economy, 1991, vol. 99, no. 3, pp. 483-499. https://doi. org/10.1086/261763

11. McCann P. Rethinking the economics of location and agglomeration. Urban Studies, 1995, vol. 32, no. 2, pp. 563-577. https://www.jstor.org/ stable/43196292 
12. McDonald F., Huang Q.H., Tsagdis D., Tuselmann H.J. Is there evidence to support porter-type cluster policies? Regional Studies, 2007, vol. 41, no. 1, pp. 39-49. https://doi.org/10.1080/00343400601136284

13. Mommaas H. Cultural clusters and the post-industrial city: Towards the remapping of urban cultural policy. Urban Studies, 2004, vol. 41, no. 3, pp. 507-532. https://doi.org/10.1080/0042098042000178663

14. Parthasarathy B. India's Silicon Valley or Silicon Valley's India? Socially embedding the computer software industry in Bangalore. International Journal of Urban and Regional Research, 2004, vol. 28, no. 3, pp. 664685. https://doi.org/10.1111/j.0309-1317.2004.00542.x

15. Phelps N.A. Clusters, dispersion and the spaces in between: For an economic geography of the banal. Urban Studies, 2004, vol. 41, no. 5-6, pp. 971-989. https://doi.org/10.1080/00420980410001675887

16. Porter M.E. The competitiveness advantage of nations. London, Basingstoke Macmillan, 1990.

17. Rosenfeld S.A. Bringing business clusters into the mainstream of economic development. European Planning Studies, 1997, vol. 5, no. 1, pp. 3-23. https://doi.org/10.1080/09654319708720381

18. Scott A.J. Location processes, urbanization, and territorial development: An exploratory essay. Environment and Planning A, 1985, vol. 17, no. 4, pp. 479-501. https://doi.org/10.1068/a170479

19. Scott A.J., Storper M. High technology industry and regional development: A theoretical critique and reconstruction. International Social Science Journal, 1987, vol. 112, pp. 215-232.

20. Tan J. Growth of industry clusters and innovation: Lessons from Beijing Zhongguancun Science Park. Journal of Business Venturing, 2006, vol. 21, no. 6, pp. 827-850. https://doi.org/10.1016/j.jbusvent.2005.06.006

21. The World Bank. World development report 2009: Reshaping economic geography. Washington DC, 2009. 383 p.

22.Zhou Y. The making of an innovative region from a centrally planned economy: Institutional evolution in Zhongguancun Science Park in Beijing. Environment and Planning A, 2005, vol. 37, vol. 6, pp. 1113-1134. https://doi.org/10.1068/a3716

23. Federal State Statistics Service. https://rosstat.gov.ru/ 


\section{ДАННЫЕ ОБ АВТОРЕ}

Гичиев Набиюла Сапиюлаевич, ведущий научный сотрудник, заведующий Отделом теории и методологии регионального развития, кандидат экономических наук

Институт социально-экономических исследований Дагестанского федерального исследовательского ичентра РАН пр. М. Ярагского, 75, г. Махачкала, Республика Дагестан, 367000, Российская Федерация nabi-05@mail.ru

\section{DATA ABOUT THE AUTHOR}

Gichiev Nabiyula Sapiyulaevich, Leading Researcher, Head of the Department of Theory and Methodology of Regional Development, Ph.D. (Economic sciences)

Institute of Socio-Economic Research of the Dagestan Federal Research Center of the Russian Academy of Sciences

75, M. Yaragsky Ave., Makhachkala, Republic of Dagestan, 367000, Russian Federation nabi-05@mail.ru 